International Journal of Linguistics, Literature and Translation (IJLLT)

ISSN: 2617-0299 (Online); ISSN: 2708-0099 (Print)

DOI: $10.32996 / \mathrm{ijllt}$

Journal Homepage: www.al-kindipublisher.com/index.php/ijllt

IJLLT

\title{
The Dynamic Dialectic and the Eclectic Plaintive Rhythm in Bembeya Jazz's, Black Beats Music
}

Souleymane Diallo

Phd Student, A R C I V Doctoral School, Postcolonial and African Studies Laboratory, Anglophone Department, Cheikh Anta Diop

University, Dakar, Senegal

Corresponding Author: Souleymane Diallo, E-mail: jahsalomon@gmail.com

ARTICLE INFORMATION

Received: December 17, 2020

Accepted: February 04, 2021

Volume: 4

Issue: 2

DOI: 10.32996/ijllt.2021.4.2.7

\section{KEYWORDS}

Post-independent, Nationalism, Imagery, Influence, Music, Narrative discourse

\section{ABSTRACT}

The foremost line of the post-independent music evolves especially, from a simple to a more compound whole within the understanding of convention of representation and the association of experience become structural materials. Thereby, the basic component of conventional imagery, and the colonialist dynamic straightforward influences frame a new idiosyncratic type that evaluates the establishment of realty, memory and symbol. Correspondingly, through the foundation of intellectual and artistic image, the commensurate imagination of the musical nationalism schedule moves afar unconscious and insensate sensitivity. Indeed, the cultural and artistic body of the Bembeya Jazz and the Black Beats Band deconstruct the colonialist conventional perception of productivity; then, through extensive collective relation with their time and space, their nationalistic music exhibits boundaries of crossexamination regarding the realm of recombination, reconciliation and reappropriation. Within the respect of material imagination and objective reality, verbal text, and contemporary Western musical instruments become the developing artistic cosmos within a new social and linguistic narrative is structured. Hence, the commitment of this article stands as a diagnostic process within we try to grasp the rapport of the indigenous value of imagination and the transcontinental stylistic effects inside the historio-context of redefining the self, sociolinguistic reflectivity, and perceptive sensibility in post-independent era.

\section{Introduction}

The formally renouncement and the completely withdrawal to the material affairs of the theoretical and practical colonial order of instruction, brought the post independent setting, and its musical nationalism to installing a formal statement inspired from a high authority of traditional signpost. In effect, by defining the colonialist and capitalist moral as an anathematizing method, which ideally subjugates and prohibits cultural, intellectual and artistic production by excising the colonized sensitive and plenitude moral state; the philosophy and intelligence of the post-independent artistic production moves out of the atheistic, the narrowed religious discourse and the politico-economic suprematism to ingrain a revolutionary socialist harmonic developing organism.

Hence, through the installment of a back label, and the bearing of the post-independent platform, and the hallmark of a counter-balancing transitional social state, art and particularly music stands as a moral method that discloses the morbid fascination of colonial domination, individual and social misery and extreme intellectual poverty. It is within this respect, the Guinean Bembeya Jazz Orchestra and the Ghanaian Black Beats Band, through a particular artistic vision, intellectual material and in a substantial linguistic reality, underline a new musical purchased order, which focuses on the impoverishment of the collective vital forces, and intellectual and emotional disintegrating. Therefore, the indigenously new art, by standing against the colonial rational eccentricity, and by negating the sacrosanct western perception of moral and socio-economic structures, determines a multi-articulated transition as regards self-re-appropriation and national consciousness. Intellectuals and

K C AL-KINDI CENTER R D FOR RESEARCH AND DEVELOPMENT Your gateway to world-class research

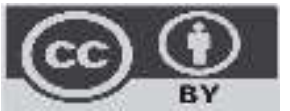

Published by Al-Kindi Center for Research and Development. Copyright (c) the author(s). This open access article is distributed under a Creative Commons Attribution (CC-BY) 4.0 license 
specifically those evolving within the realm of music embody the ordering of a new multimedia that consist of a gathering technic of cultural and identity reconciliation communication.

Correspondingly, from a traditional pentatonic style to a foremost diatonic weighbridge, the socially responsive artistic phenomenon throughout the post-independent program, defines a de-culturized vision. It is in this respect; the main line of this paper focuses on the interest and the belief of practical application of music and diverse musical instruments through the aesthetic and rational organization as regards nationalistic and post-independent program. In the next section, I discuss the trans-national social dynamic, embedded in a combative language in support of a socio-political cause, and identity reconstruction, in the succeeding section, I deal with the variety of an interactively artistic and communicative framework outlined within a psychological and plaintive rhythm.

\section{The Popular Spoken and the Major Anthropological Break}

From Western and Islamic influences, the post-independent musical nationalism discloses architectural paradigms concerning cultural re-appropriation and identity formation. Indeed, emphasizing on traditional method of intellectual and artistic stimulation, which is efficiently within the bounds of language and the rhetorical approach of the long-established traditional authority, and then, to the western humanistic and analytical method that stresses itself on comparative cultural and intellectual production, the African post-independent popular music exceptionally fast-track the compulsory active form of duty. It is within this respect, the stylistic development of Mbaqanga in South Africa, the Taarab music in East Africa, the Soukous and Makoussa in Central Africa, the Rai in North Africa, and the paradigmatic West African highlife music, underscore an energetic translation of ideas, and a harmonization of a scientific and artistic sphere of progress. In this line of ideas, through a superposition of traditional method and contemporary understanding the Guinean Bembeya Jazz Orchestra and the Ghanaian Black Beats Band, involve a course of action denoting purity and quality, and within the same run, redefining the intellectual and moral values of traditional African style, in the dynamic to fulfill the contemporary promises of revalorization and revolution. Beyond the frame of entertainment and by integrating the emotional effect of western musical genres and instruments; these artists heavily implicate themselves in an active dialectic, and in a tastefully value renewal within which neo-colonial appropriate principles to the significance of being, civilization and progress are sufficiently and methodically established as the basic line of the African renaissance. It is within this respect, we grasp Ngugui Wa Thiongo's observation when he writes:

The resistance tradition is being carried out by the working people (the peasantry and the proletariat) aided by patriotic students, intellectuals (academic and non-academic), soldiers and other progressive elements petty middle class. This resistance is reflected in their patriotic defence peasant/worker roots of national cultures, their defence of the democratic struggle in all the nationalities inhabiting the same territory. Any blow against imperialism, no matter the ethnic and regional origins of the blow, is a victory for all anti-imperialistic elements in all the nationalities. The sum total of all these blows no matter what their weight, size, scale, location in time and space makes the national heritage (Wa Thiong'o, 1986, p. 02).

Thereby, on the sources of a relation social communication, the language of the people that efficiently stamps the architecture of the musical nationalism, forcefully, enlightens traditional rhetoric, and then removes the western burden of political discourse, to insert an artistic production for the people with beliefs appropriate to their time. In fact, the assimilation of ideas, material and experience throughout the post-independent musical agenda, has instituted a revival process as regards African arts, and most particularly Guinean and Ghanaian musical nationalism and languages, which stand sufficiently enriched and to become an influential intermediate for the new sociopolitical ideas that characterize the political and artistic picture. In effect, from traditional balafon (xylophone) kora (harp) nkoni (lute) to acoustic guitar, the rising musical repertoire remains mostly oratorical, confrontational and an immediate influence. Artists patriotic feeling designs the main traits of musical outputs, therefore, the nationalist discourse becomes the back bourn of a variety of an interactively artistic and communicative framework. Thus, Tanure Ojaide states that:

Literature in Africa has traditionally played a transformative role in society. Satiric or abuse songs, such as the udje of Nigeria's Urhobo people and the halo of the Ewe of Ghana and Togo, are composed to check the excesses of individuals in a communal society through insults of those violating the accepted communal virtues and ethos. One can say that the Yoruba ijala and the Zulu and Tswana izibongo, by praising individuals in society with the virtues of courage, generosity, and others, also stir people to strive for such virtues. Oral narratives, especially epics, such as of Sundiata, Ozidi, and Mwindo, engage in stirring up a sense of heroism in individuals among their peoples ( Ojaide, 2009, p. 4). 
Moreover, with the indigenization of the western musical instruments, a logical and a processing crystallization of tradition in memory, throughout political positioning and in popular resistance appears as a reality. Thus, traditional style of repetition, storytelling become ingrained in a modernized and Africanized musical smartness, determined by an anti-colonial reconvening This backdrop of increasing nationalist and cultural identity sensitivity puts forth the renewal of language; afterward, inside the blending of modern and traditional musical instruments, language stands as a trancelike state, with its soul ideas of reconciling the self with its cultural epitome. Thus, the jingoistic leitmotifs in the post-independent package revives the frame of the colonized language; subsequently, involving it in a proficiency of mystic self-transcendence. Within this respect, the projected narrative voice in this nationalistic music, involves a highly textual voice, which steadies up popular spoken frame, in a line, it absorbs in its own manner story actions, and establishes practical and appropriate voice project to receive and address with its own psycho-affective perception. Indeed, the setting of narrative discourse in this post-independent music deconstructs the content matter of Western basis of discourse, and then on varied methods molds inherently, and aesthetically an apposite voice to be existing and idiosyncratic value as regards the orthodox arrangement of artistic narrative and communication:

It is an ever-continuing struggle to seize back their creative initiative in history through a real control of all the means of communal self-definition in time and space. The choice of language and the use to which language is put is central to a people's definition of themselves in relation to the entire universe. Hence language has always been at the heart of the two contending social forces in the Africa of the twentieth century (Wa Thong'o, 1986, p. 4).

Throughout the imaginative re-appropriation and aesthetic reformulation, the narrative discourse that sustains the musical structures and effectiveness of Bembeya Jazz Orchestra and the Black Beats Band, emphasizes on practical considerations and material of the narrative condition that is the recipient "YOU". By this means, through conventional occurrences, informative requirements and intellectual faculties, the narrative discourse inside this artistic outputs unveils an accurate, appropriate intonation that yields a signal of language and emotion composition. Therefore, in the run of the subjective countenance of this musical nationalism, which efficiently delineates their political value, ideological coordination, and attitude regarding people, we grasp a belief to a function and a purpose and consequently assignments a determined concreate, distinctive voice. Thereby, with the rising of African socialism process powered by leaders of the epoch, new acts of changing were stimulated not only of the framework of politics, but in the same manner, in intellection, imagination and criticism. Indeed, by taking into account the ancient oral tradition, narrating the mythical symbols or the history of nations, the Bembeya Jazz Orchestra and the Black Beats Band post-independent musical schedules forge a logical, and a sensible popularization of the cognitive structures of meaning. It is within this framework, Celestine Chukwuemeka Mbaegbu argues that:

The African see music as a weapon for correcting moral deviants and as a medium through which a lost society can be shocked back to life. Consequently, some classes of African music, namely traditional can therefore be regarded as a herald or vanguard of moral change because African folk musicians make conscious attempt to use their brand of music to influence behavior. Music in Africa is a call to service, a medium through which an earring and ignorant can be shocked back to awareness, inculcate and re-enforce social norms and values while some music forms in Africa especially the parabasis, which is usually the end of the story, witnesses the musicians telling the moral of the story as well as warning and advising the audience on future courses of action. A critical look at the forms or arrangement of parts of African Traditional music will reveal instantly that they are deliberately arranged to enhance the teaching of morals (Mbaegbu, 2015, p. 181).

Thus, post independent artists, and mostly, the new generation namely Sekou Bembeya Diabate, Sidiki Diabate, Kerfala "papa", Sekou "Docteur" from Guinea and the Ghanaian King Bruce, Lewis Wadawa, Frank Barnes, E. T. Mensah to name only, define a new model of logical aspect of significance, within implication and sensational accuracy have to be expressed in an innovative and immediate enlightening modus operandi. Therefore, popular spoken through new paradigms for public art and within a new way of Western material innovations strides confidently in an inclusive mêlée, and in an imagination parallel with their new social anthropological realities. Within the respect of this sociocultural transformation and imaginative intercourse, political, musical, moral education and the familiarity of foreign influences and languages become entangle with a shared enthusiasm, contemporary fashion and denotes their intelligence on their traditional and nationalistic experience. Correspondingly, Austin Emielu declares that:

The formation of what may be described as African brass bands marked the climax of the indigenisation process and prepared the ground for the eventual syncretisation of Western and African musical resources to produce the Highlife format as recognized today. It is interesting to note that the name 'Highlife' coined at the indigenisation stage. This was done as an attempt to demarcate local tunes played by local folks on local 
instruments in local venues, from tunes orchestrated and played on Western instruments in exclusively nontraditional contexts (Emielu, 2011, p. 378).

From a Marxist, socialist and realistic perspective, the musical nationalism of the Bembeya Jazz Orchestra and the Black Beats Band was original not only in substance, but in modus vivendi. It is in this dynamic, the musical program of the 1950's and 60's appears to be the furthermost resourceful in the history of art, thereby, defining an all-inclusive innovative bearing to the advancement of anthropological sensitivity and consciousness. This early nationalistic music is partly accountable and influential for the inordinate transformations that have overtaken the African musical formulae. This fact remains well illustrated through tracks like "Beni Barale", "Loi-Cadre", "Guinee Hety Horemoun", "Petit Sekou", "Republique Guinee" from Bembeya jazz, and "Nkuse Mbaa Dong" (I'll Never Return), "Teeman Sane" (A Confidential Matter"), "Momo Koko" (A Thing of Joy) to name only from Black Beats. It is meaningful that with the introduction of this pronounced inspiration in the African world, our own creative free-for-all about institution and the individual endowment becomes a center.

\section{The Usage of the Ordinary for the Collective Memory}

The disconcertingly plasticity of autochthon African languages, and the extreme flexibility of the invaders' languages; intellectual and artistic influences have always aroused a very inquisitive object, which in the same frame, determines a new communicative dynamism method. In effect, being concerned to widen the boundaries, the independence, and the quality of the musical nationalism program, the Bembeya Jazz Orchestra, and The Black Beats Band actually, establish a clear-cut guideline, and a methodically definition of the effects of language therein oversimplification and generalization are efficiently forbidden for the matter of subject-base pedagogies. Thereby, the popular imagery, and the sensible and practical idea that characterize the run of musical nationalism, emphasize on the distinction between spoken language and written word, and then, the cultural differences as regard artistic and literary materialization and substantial arts. Therefore, the psycho-affective perception of intellection throughout the realm of music and through the Western cultural influences, appears to be a social issue of a great significance. In this sense, the often cited Ngugui Wa Thiong'o declares that:

The verbal signpost both reflect and aid communication or the relations established between human beings in the production of their means of life. Language as a system of verbal signposts makes that production possible. The spoken word is to relations between human beings what the hand is to the relations between human beings and nature. The hand through tools mediates between human beings and nature and forms the language of real life: spoken words mediate between human beings and form the language of speech (Wa Thong'o, 1986, p.14).

By this way, cultural knowledge stands as a collective responsibility within the ordered and detailed instruction of collective memory emerges from the indigenized ideological influences of artistic and literary engagement concerning tradition, and the individual endowment performs as a manifesto. Indeed, from a new aesthetic attitude, and an intelligibility of communication, the new nationalistic music amplifies the basically traditionalist experience, and then introduces artistic liberal methodologies, which becomes uplifting central position throughout inculcating in the collective memory the necessary moral and didactic elements for the required revolution. Through a practical criticism and by understanding art as being a consequence of a definite circumstance, the music of independence across the popular oral narratives of the ordinary country people, alters the natural quality of the Western conventional verbal propriety; and therefore, destroying the artificiality characteristic decorum of Western artistic language. Thus, outside the traditional dogmatic verbal texture, the Bembeya Jazz Orchestra and the Black Beats Band anticipate on the effective correlation between ordinary language and contemporary issues; mutually supporting and harmonizing the interrelationship influences between the whole and the part of the quintessential unity of collective memory. Consequently, Austin Emielu argues that:

Social reconstructionism' is based on my perception of African popular music as a social concept which is constructed or created through prevailing socio-historical processes. Social reconstructionism as a theory posits that a socially constructed phenomenon can be socially deconstructed and socially reconstructed contingent upon prevailing socio-historical processes' (Emielu, 2011, p. 379).

In this framework, the stylistic particularities of the post-independent nationalistic music, over a historical sense install a new deal of authority therein the essence of collective memory happens no longer as the simple congregation of folklore; however, the classical stream influences the increasing predisposition, further, the innovative ingather varieties accommodates the relation and the proportion of the tradition construction of collective memory. Correspondingly, throughout the fascinating mix of the traditional sensitivities and the indigenized interactive artistic method, the cognizance of change becomes a main release that authors and artists insist on. Then, correlativity, and subjectivity stand as a corresponding center within customary inclusivism and the organic accumulation and unity of the work of art determine the already acquired and experienced collective memory and image. It is within this respect, through the effect of connection and transformation, the nationalistic musical package 
installed inside the state-nation building of Guinea and Ghana develops inside the redefinition of collective memory, a factual intelligence of responsiveness concerning the history of tradition in the past and its currently objective presence. Consequently, the new artistic technics, influences and ordinary country languages deconstruct the Western devasting socio-political establishment and works of literature and art, which efficiently figured the broken and fragmented image inside the There-being, and the symbolic order of the autochthon civilizations. Within the respect of line, Eric Charry writes:

The rise of modern Mande music began in earnest with the Guinean independence in 1958. The new government launched a sweeping modernization policy in which European musical instruments (including electric guitars) were handed out, musicians were made civil servants, and a network of regional and national orchestras was established. Jelis used the electric guitar as the main vehicle for transferring their local repertoires to these new urban electric group. In their hands, the guitar maintained the integrity of traditions which it had absorbed, and it spawned new and virtuosic styles of playing (Charry, 1994, p. 21).

From the ruins of a fragmented cultural system to a nationalistic political discourse, composition of the independence remains an interface communication within collective memory construction is encumbered. In effect, the sequential interaction between oral tradition and modern Western influences bring the individual to remain within his self-imposed precincts of tradition, and in the same way to transcend them by spellbinding the nationalistic and the imagery magnitude of identity perception in hand. The organically ordinary whole responds, therefore to a mature of transcending the subjective to the collective; thus, the history of people, the natural and social phenomenon understructure the musical nationalism of the Bembeya Jazz Orchestra and the Black Beats Band. Moreover, by restoring the truthfulness of the ancient rituals, the words of music put the realm of collective memory in a new scale of imagination, production and inventive process throughout the most long-term sophistication. Therefore, Celestine Chukwuemeka Mbaegbu states that:

African moral judgments are principally based on their world view; good and bad in African society therefore depend on their conception of the universe and his place in it. Such moral value judgments are made with particular reference to the practical realities of life of the individual and the society (Mbaegbu, 2011, p. 178).

Throughout the experienced post-independent misfortune, artists overpoweringly define a responsive and reactive exhaust system, a whole order of effects and leitmotifs, and most essentially marks out the boundaries of collective imagery out of the subject of the sterile. In addition, idealism being originally part of the African socio-anthropological imagination, creativity and excitement, it becomes naturally involved in the artistic production of the epoch. This datum facilitates an intensive didactic method, and profound immersion of the collective imagery through the meaning of sacrifice and the significant symbol of the quality to bring into straight and premixed involvement with the immediate identified causes. This balance becomes explicitly a manifestation of the music produced throughout the artistic nationalism frame, these symbols have been continually expended; consequently, their significance, corresponding and representationism present methodically, and in features principles and concepts, which have reciprocal relationship with the prominence of collective memory.

\section{The Psycho-Criticism Panorama of Sound and Mind}

The influential connection and the methodical derivative weights that characterize the established structures of colonial subjugation, and technological experience impel within the artistic development of the post-independent new generation, innovative approach of learning, themes and imagery. From a putative measure from traditional styles and values to a neoconservative varieties, the nationalistic music becomes a liberal and radical section of the nationalist political discourse. In effect, the complete new intellectual and artistic movement cherish the stimulation and the social avant-gardism theories, which imagine the complete disintegration of the Western unenthusiastic and unfamiliar spirit; therefore, articulating an optimum historical and psychological circumstances to revitalize autochthon's creativity, ideas and stylistic expression. Within this respect, the poetic and free verse style that design the narrative discourse of the Bembeya Jazz Orchestra and the Black Beats Band dive themselves inside the Western echoing intellection and imagination; thus, typographically decomposing these influences into multiplatform means of expression and communication crossroad. It is in this sense Walter Ong's words through his work Orality and Literacy, bear all the propensity essence of the post-independent music. He writes:

Oral cultures indeed produce powerful and beautiful verbal performances of high artistic and human worth, which are no longer even possible once writing has taken possession of the psyche. Nevertheless, without writing, human consciousness cannot achieve its fuller potentials, cannot produce other beautiful and powerful creations. In this sense, orality needs to produce and is destined to produce writing. Literacy, as will be seen, is absolutely necessary for the development not only of science but also of history, philosophy, explicative understanding of literature and of any art, and indeed for the explanation of language (including oral speech) 
itself There is hardly an oral culture or a predominantly oral culture left in the world today that is not somehow aware of the vast complex of powers forever inaccessible without literacy (Ong, 2002, p.14).

Consequently, the organic matter of the post-independent musical nationalism, and the faculty of consciousness and thought of these new generation artists crystallize a conceptual art, with its immutability in terms of content and affective order, forcefully, evolves from a subliminally sacrosanct state to a representative criticism. Indeed, outside the pervasively unproductive colonial mind-bending, the syncretizing new sound emphasize on overcoming methodical proceeding narrative purposes within characters varieties and images become an absorbing account of a wide variety of nationalistic work and psycho-acoustic objects of the ritualized modes of social behavior. In this run, the perception of sound and its psychological effects bring the Bembeya Jazz Orchestra and the Black Beats Band to involve their musical nationalism in a framework of reflectivity; thus, the assortment of comprehensive system, basic component, and simplistic convenience understructure and bring to the conscious mind an asset of response regrading cultural identification, and creative possibilities from the individual. Thereby, the principles and techniques of perceiving sensitivity and performing throughout the prospect of sound and mind, go beyond the determinative issue of relationship; however, they exhibit the archetypal art of contemplation, behavior, liberation, and power relation. This sense of purpose that underlines the history and the institutions of the indigenous people, signals a mental and emotional paradigm shift, a structural deconditioning of cultural material productions, which essentially effect social construction and power relation. Thus, Ruth Finnegan argues that:

It has been well said that oral poetry takes the place of newspapers among non- literate peoples. Songs can be used to report and comment on current affairs, for political pressure, for propaganda, and to reflect and mould public opinion. This political and topical function can be an aspect of many of the types of poetry already discussed-work songs, lyric, praise poetry, even at times something as simple as a lullaby...The political role of poetry is not just of recent origin in Africa. It is true that the present widespread occurrence of political songs directly associated with modern political parties and national politics did not antedate the founding of such organizations and their relevance in the contemporary political scene. But it would be a very narrow view of politics that would confine it only to the affairs of political parties or the formal institutions of modern nation states (Finnegan, 2012, p. 265).

Therefore, the deterministic psycho-criticism that transcends the conceptual and practical field of the musical nationalism agenda, is exhilarated by the sense of purpose of human consciousness based on, an African socialist ideology, nested throughout traditional concepts of standards, opinions, affective perception, and self-own relation expression of reality. Then, outside the completely focuses on aesthetic fundamentals, the African popular music, and particularly the one produced by Bembeya Jazz, and the Black Beats enlightens the African cognoscenti, and its artistic ethnic bounds organization. Correspondingly, this perspective unveils an intentional simplicity to synchronize the understanding of artistic productions with the established set attitude of the era, the prevailing ideology within we observe artistic articulation and creation, and determinedly analyzing the connection between the macrocosm of the musical expression and the social representativeness of the interval and place. This fact is well illustrated inside the run of African Pop Music since the Independence Era, while Hauke Dorsch writes:

Many political active musicians either fled into exile or were forced into it. Among these, Mariam Makeba and Hugh Masekela are the most famous... she realized that critical voice were not always welcome in the West, either. Stages of performances were cancelled, she found herself exposed to hostility... into exile to Guinea, where Makeba was not only supported y Sekou Toure... Incidentally, she learned the art of griot praise-singing in Guinea, and practiced it right away in honor of Sekou Toure (Dorsch, 2010, p.14).

This dimension of musical nationalism brings forth new attitudes and attributes inside the subtle interrelationship of artistic production and languages that cease to be objective and self-sufficient object. Throughout the psycho-criticism of mind and sound, it appears that the music of independence, systematically, moves out of the western scheme of scientific and practical discourse, and then absorbs a logical matter of meanings and interactions of the dialects of people, figures and symbols. By this means, throughout this correlative method, it becomes more perceptible that the intellectual production, and more specifically the musical line of the independence through its external influences and within its specific historical authorities, detaches itself from the traditional conception of a work as a completed configuration of meanings. Consequently, the quintessence and the circumstance of being of this music must be translated into a psycho-affective endeavor and then structures, varieties, and narrative discourse become significant only inside the correlation between self-experience and the circumstance settings of an event. It within this respect we understand Shiqi Zhang argument: 
Music, as an important form of artistic expression, has long been a part of art research. In recent years, with the rapid development of brain imaging technologies such as event-related potential (ERP), electroencephalography $(\mathrm{EEG})$, magnetoencephalography (MEG), and functional magnetic resonance imaging (fMRI), music has gradually been incorporated into cognitive neuroscience. Brain plasticity means that the brain can be modified by the environment and experience, and has the ability to shape the structure and function of the brain under the influence of the external environment and experience (Zhang, 2020, p.5).

Accordingly, the customary unit expended to measure the intensity of sound, and the deep-rooted power level propelled to justify rhetoric appear overtaken for a beyond sensible and functional use of language and musical instruments. Then, words become a simple life-form system, and its effective usage inside the transposition of traditional musical style to Western modern musical tool, exhibits an additional upfront transcending instantaneous influence. Throughout the psychoacoustic realm that underlines the intensity and the performance equipment of the Bembeya Jazz Ochestra and the Black Beats Band, we observe the new focus of these artists throughout the musical nationalism agenda, remains the composition of an independent oratorio throughout the manipulation of language, symbols, metaphor. Thus, this domain happens to be a complex network, and a quantity containing, which strives to streamline the structures of meaning and the multiplicity of intensities for their consequences.

\section{Conclusion}

The post-independent musical nationalism agenda becomes an extensive and a multiform repository within which cultural energy, and the schemes of familiarity, its cogency, opportunity and otherness regarding acceptance structuration and opinion rationalization are reinvented par rapport the standards and reasons relevant to the meaning of life, society and movement. In effect, throughout the different cultural, intellectual and musical influences that have stamped the course of history of these African societies, the musical nationalism program and particularly, the musical general release of the Bembeya Jazz and the Black Beats overcomes the colonialist and classist intellectual and productive method of art. Through a synthesis orthodoxy and a contemporaneous revolution, the legal and moral instruction of the music of independence, defines innovative contour as it regards the African renaissance. Thus, from the insistent conventional rhetoric to peripheral, operative and diverse influences, the language of the country people undergoes an increasing intellection revitalization to create for the people a containing discourse and artistic consequence with ideas and ideals relevant to their instance.

Throughout the socialist ideology and language, and inside the awareness of their cultural and political isolation, the transposition of oral technics into the Western mode of intellection and imagery creation, establishes a structural sensitive and sensible revolution of their intellectual animation. Therefore, this new psycho-affective frame stimulates not merely constitutional response, but, it forcefully magnets an oversensitive grasp concerning the focus on interrelation of social factors and individual thought and behavior, criticism and immediate artistic imagination and expression.

Realistically, the African popular music throughout the voice, and musical proficiency of the Bembeya Jazz Orchestra and the Black Beats Band, embodies the range of experience and thought in a different sprightly, and furthers intuitive conviction by involving affectivity in an open imagination equivalent with their determination. Within the consequence of dimension and quantity the post-independent musical imagination influences the prompt coverage of culture and the understanding of transcontinental languages and experiences. This frame brings local languages and artistic functional productive materials to unrestraint themselves inside contemporary techniques and in a challenge to manage their imagery and experience.

\section{References}

[1] Charry, E. (1994). The grand Mande guitar tradition of the Western Sahel and Savannah. The world of music, 21-61.

[2] Collins, J. (1989). The early history of West African highlife music. Popular Music, 8(3), 221-230.

[3] CULLER, J. (1997- 2000). Literary Theory: A Very Short Introduction. Oxford University Press.

[4] DAVE, N. (2017). Music Multipartism and the "Guinean Family". In The World of Music, Sound Ethnicity: New Perspectives on Music, Identity, and Place, 6(2), 115-130.

[5] Davidson, R. A. (1997). A question of freedom: African Americans and Ghanaian Independence. Negro History Bulletin, 60(3), 6-12.

[6] Dorsch, H. (2010). "Indépendance Cha Cha": African Pop Music since the Independence Era. Africa Spectrum, 45(3), 131-146.

[7] Emielu, A. (2011). Some theoretical perspectives on African popular music. Popular Music, 371-388.

[8] FINNEGAN, R. (2012). Oral Literature in Africa, In World Oral Literature Series, Vol.1, Devonshire Road, Cambridge, CB1 2BL, United Kingdom, Open Book Publishers CIC Ltd.

[9] MBAEGBU, Celestine C. ( 2015). The Effective Power of Music in Africa. In Scientific Research Publishing Inc. http://dx.doi.org/10.4236/ojpp.2015.53021

[10] Munyaradzi, G., \& Zimidzi, W. (2012). Comparison of Western music and African music. Creative Education, 3(2), 193195.http://dx.doi.org/10.4236/ce.2012.32030

[11] Ojaide, T. (2009). Examining canonisation in modern African literature. Asiatic: IIUM Journal of English Language and Literature, 3(1), 1-20. 
[12] ONG, Walter J. (1982- 2002). Orality and Literacy: The Technologizing of the Word. London, New York, Routledge.

[13] Robertson, C. (2015). Whose Music, Whose Country? Music, Mobilization, and Social Change in North Africa. African Conflict and Peacebuilding Review, 5(1), 66-87.

[14] WA THIONGO, N. (1986). Decolonizing the Mind: The Politics of Language in African Literature, London, Heinemann,

[15] Zhang, S. (2020). The Positive Influence of Music on the Human Brain. Journal of Behavioral and Brain Science, 10(1), 95-104. https://doi.org/10.4236/jbbs.2020.101005 